Arq. Bras. Med. Vet. Zootec., v.67, n.2, p.347-352, 2015

\title{
Cistopexia videoassistida em cadela com cistocele após prolapso uterino: relato de caso
}

\author{
[Videoassisted cystopexy on a female dog with cystocele after \\ uterine prolapse: a case report] \\ T. Krebs ${ }^{1}$, M.V. Brun ${ }^{2}$, M.T. Linhares ${ }^{3}$, F. Dalmolin ${ }^{1}$, V.H. Pohl ${ }^{1}$, J.P.S. Feranti ${ }^{1}$ \\ ${ }^{1}$ Aluno de pós-graduação - Universidade Federal de Santa Maria - Santa Maria, RS \\ ${ }^{2}$ Universidade Federal de Santa Maria - Santa Maria, RS \\ ${ }^{3}$ Residência - Universidade Federal de Santa Maria - Santa Maria, RS
}

\section{RESUMO}

O prolapso de vesícula urinária associado ao prolapso uterino é condição rara em cães e gatos. O tratamento preconizado para essa afecção é o reposicionamento anatômico das estruturas afetadas. No presente relato é descrito o manejo por meio de ovariossalpingo-histerectomia por celiotomia e, após dois dias, cistopexia videoassistida. Essa condição, conforme o conhecimento dos autores, não havia sido previamente descrita. A operação apresentou-se como possibilidade viável de tratamento, sem complicações pós-operatórias.

Palavras-chave: videocirurgia, retroflexão vesical, vesícula urinária, prolapso, canino

\begin{abstract}
The urinary bladder prolapse associated with the uterus is a rare condition on dogs and cats. The recommended treatment is the anatomical repositioning of the affected structures by manual reduction or surgery procedure. The present report describes the management by video-assisted cystopexy two days after conventional ovariohysterectomy. This condition, according to the authors' knowledge, had not been previously described. The operation didn't showed postoperative complications, and presented itself as a viable treatment option.
\end{abstract}

Keywords: videosurgery, bladder retroflection, urinary bladder, prolapse, canine

\section{INTRODUÇÃO}

O prolapso uterino é condição rara em cadelas e gatas (Stone, 2007). É definido como a eversão e protrusão de uma porção do útero pela cérvix para dentro da vagina durante o parto ou próximo dele (Hedlund, 2008). Um corno ou todo o útero pode sofrer prolapso durante o parto prolongado, ou até 48 horas após esse evento, quando a cérvix se apresenta extremamente dilatada (Stone, 2007). Muitas espécies animais podem ser afetadas por prolapso de órgão genital, podendo este estar associado a outros órgãos, como a vesícula urinária e a porção distal do cólon (Hedlund, 2008).

Recebido em 13 de junho de 2014

Aceito em 9 de janeiro de 2015

E-mail: tami.kbs@gmail.com
A protrusão (ou prolapso) da vesícula urinária para o interior da vagina é denominada cistocele. Esta resulta de perda de continuidade da fáscia pubocervical, que funciona como suporte para a bexiga, condição raramente relatada na medicina veterinária (Besalti e Ergin, 2012).

Besalti e Ergin (2012) descreveram a cistopexia como tratamento para cistocele em uma cadela que também apresentava prolapso retal. Esse procedimento permite a fixação permanente da bexiga à parede abdominal, sendo indicado para prevenir a transformação de uma hérnia vesical recidivante em hérnia perineal e para o tratamento de incontinência urinária associada à localização pélvica da bexiga (Waldron, 2007). 
A laparoscopia é uma abordagem minimamente invasiva, que proporciona a visualização das estruturas internas da cavidade abdominal, para fins diagnósticos e realização de diversos procedimentos cirúrgicos. A pouca invasividade, a baixa porcentagem de complicações, a baixa mortalidade e o menor tempo de internação dos pacientes auxiliam na rápida recuperação dos animais e implicam maior satisfação dos proprietários (Matyjasik et al., 2011).

O presente trabalho tem como objetivo descrever um caso de prolapso uterino e cistocele em uma fêmea canina bem como seu tratamento bemsucedido por meio de ovariossalpingohisterectomia $(\mathrm{OSH})$ por celiotomia e posterior cistopexia videoassistida, condição ainda não relatada segundo o conhecimento dos autores.

\section{CASUÍSTICA}

Foi atendida, no Hospital Veterinário Universitário (HVU) da Universidade Federal de Santa Maria (UFSM), uma cadela da raça Collie, 13 anos de idade, pesando 20,8kg, que apresentou histórico de parto distócico e presença de feto morto no canal do parto, o qual, após dois dias, foi expulso, ocorrendo também prolapso uterino. A paciente havia recebido atendimento em outro estabelecimento, quando foi realizado tratamento com enrofloxacino em dose única. $\mathrm{O}$ animal estava prostrado, apresentando disúria e disquesia. Ao exame clínico, constataram-se estado nutricional ruim, desidratação de $10 \%$, mucosas rosa-pálidas e temperatura retal de $38,3^{\circ} \mathrm{C}$. Foram observados aumento de volume em região vulvar, grande quantidade de secreção purulenta e sujidades (Fig.1). Obteve-se o diagnóstico de prolapso uterino.

Realizou-se limpeza da massa protruída por meio de lavagem exaustiva com solução de cloreto de sódio $0,9 \%$ e aplicação de açúcar cristal para diminuir o edema local e tentar reduzir o prolapso uterino manualmente. Como isso não aconteceu, a paciente foi encaminhada para cirurgia de redução do prolapso uterino e OSH terapêutica pela técnica convencional.

Foram coletadas amostras de sangue para avaliação de hemograma e bioquímica sérica. Observaram-se anemia normocíticanormocrômica $(\mathrm{HT}=31,5 \%$, hemoglobina $=$
$10,8 \mathrm{~g} / \mathrm{dL}$, hemácias $=4,54 / \mu \mathrm{L}, \mathrm{VCM}=69,4 \mathrm{fL}$, $\mathrm{CHCM}=34,2 \%)$ e intensa leucocitose (63300 leucócitos totais $/ \mu \mathrm{L})$ devido ao elevado número de neutrófilos segmentados $(58236 / \mu \mathrm{L})$. Na avaliação bioquímica, observouse hipoalbuminemia $(1,43 \mathrm{~g} / \mathrm{dL})$.

Como medicação pré-anestésica utilizaram-se diazepam $(0,3 \mathrm{mg} / \mathrm{kg}$, i.v. $)$ e tramadol $(2 \mathrm{mg} / \mathrm{kg}$, i.v.); para quimioprofilaxia antimicrobiana, foi administrada cefalotina $(30 \mathrm{mg} / \mathrm{kg}$, i.v.). A indução anestésica foi obtida com propofol (4mg/kg, i.v.), e a manutenção realizada com isoflurano vaporizado em $\mathrm{O}_{2}$ ao efeito. Também se administrou dipirona $(25 \mathrm{mg} / \mathrm{kg}$, i.v.) no transoperatório.

Após ampla tricotomia em região abdominal, realizou-se a OSH por celiotomia. Os cornos uterinos foram visualizados e tracionados para o interior da cavidade abdominal, a fim de se realizar a redução do prolapso. Com a ajuda de um auxiliar, os cornos uterinos foram empurrados através da abertura vulvar e reposicionados na cavidade abdominal. Observou-se que a vesícula urinária foi reposicionada juntamente com os cornos uterinos, diagnosticando-se, assim, a presença de uma cistocele associada ao prolapso de útero.

A ligadura dos pedículos ovarianos e do corpo uterino foi realizada com fio de náilon monofilamentar 2-0. Para a síntese da parede abdominal, utilizou-se sutura padrão Sultan, fio de náilon monofilamentar 0 ; para o tecido subcutâneo, padrão zigue-zague, fio poliglactina 910 2-0; e, para a pele, padrão Wolff, fio de náilon monofilamentar 3-0.

A paciente permaneceu sob observação no setor de internação do HVU - UFSM, com a prescrição de tramadol $(4 \mathrm{mg} / \mathrm{kg}$, s.c.), dipirona (25mg/kg, i.v.), metronidazol (15mg/kg, i.v.) e cefalotina (30mg/kg, i.v.). Dois dias após a OSH, a paciente apresentou novamente aumento de volume na região vulvar, sendo constatada recidiva do prolapso vesical, e o tratamento proposto foi fixação cirúrgica da vesícula urinária à parede abdominal por meio de videocirurgia assistida.

Para o procedimento de cistopexia videoassistida, foram utilizados midazolam $(0,2 \mathrm{mg} / \mathrm{kg}$, i.m.); como medicação pré- 
anestésica, propofol (3mg/kg, i.v.) para indução e isoflurano vaporizado em $\mathrm{O}_{2}$ ao efeito para manutenção anestésica. Para analgesia, foi administrada morfina $(0,5 \mathrm{mg} / \mathrm{kg}$, i.m. $)$, e, para quimioprofilaxia antimicrobiana, ampicilina (25mg/kg, i.v.).

O canino foi posicionado em decúbito dorsal, e foi feita antissepsia da região abdominal com álcool-iodo-álcool. Realizou-se uma incisão paramediana de aproximadamente $1,2 \mathrm{~cm}$ à direita da cicatriz umbilical para abrigar portal de $10 \mathrm{~mm}$. Procedeu-se à insuflação abdominal com $\mathrm{CO}_{2}$ para obtenção de pressão intra-abdominal de $12 \mathrm{mmHg}$, e foi introduzido outro portal de $5 \mathrm{~mm}$ caudalmente ao primeiro, no lado direito do abdômen. Com a paciente mantida na posição de Trendelenburg, a vesícula urinária foi suavemente empurrada por um volante, através da rima vulvar e do canal pélvico para o interior da cavidade abdominal. Após isso, utilizou-se pinça Babcock para apreensão e tracionamento da vesícula urinária. Com essa tração, foi possível a remoção da pinça e da bainha do segundo trocarte, permitindo, dessa maneira, a exteriorização da vesícula urinária pela ferida de acesso, a qual foi ampliada em aproximadamente $1 \mathrm{~cm}$. Foram colocados dois pontos de reparo na vesícula urinária, utilizando-se fio de náilon monofilamentar 3-0. Na sequência, por meio de técnica convencional, procedeu-se à incisão vesical nas camadas serosa e muscular. Para a cistopexia, foram realizadas duas suturas contínuas simples envolvendo a parede muscular e as camadas serosa, muscular e submucosa da bexiga com poliglactina 910 3-0 (Fig. 2). Para sutura da musculatura abdominal e do tecido subcutâneo, foram utilizados padrão Sultan e contínuo simples, fio poliglactina $910 \quad 0$. A dermorrafia foi feita com fio de náilon monofilamentar 3-0, padrão Wolff. Após tais procedimentos, realizou-se inspeção laparoscópica e posterior desinsuflação da cavidade. A sutura da ferida de acesso ao primeiro portal foi realizada de maneira semelhante à descrita anteriormente.

No período pós-operatório foi mantido mesmo protocolo medicamentoso realizado para a OSH e, após 48 horas, a paciente recebeu alta hospitalar. Decorridos oito meses do procedimento e realizado acompanhamento com o proprietário, este relatou que a paciente encontrava-se sem alterações clínicas e não havia sinais de recidiva do prolapso.

\section{DISCUSSÃO}

O prolapso de útero consiste na eversão e protrusão de uma porção do útero pela cérvix, passando pelo interior da vagina (Hedlund, 2008). É considerado uma emergência obstétrica, e sua ocorrência é rara em cães e gatos (Özyurtlu e Kaya, 2005). Pode acontecer tanto em cadelas primíparas como em multíparas durante trabalho de parto ou poucas horas após o nascimento do último filhote (Stone, 2007; Mostachio et al., 2008). De forma menos comum, no presente relato, o prolapso uterino ocorreu dois dias após parto distócico, quando o feto retido no canal pélvico foi finalmente expulso.

As causas envolvidas na ocorrência do prolapso uterino não estão bem esclarecidas, porém acredita-se que alterações que envolvem relaxamento da musculatura pélvica, atonia uterina, separação incompleta das membranas placentárias, flacidez mesovariana, tenesmo e contrações uterinas excessivas são fatores potenciais (Özyurtlu e Kaya, 2005).

Os animais atendidos imediatamente após a ocorrência do prolapso encontram-se comumente saudáveis. Se o tempo de evolução for superior a seis horas, podem ocorrer anorexia, sinais de choque hipovolêmico ou séptico (Mostachio et al., 2008), sinais de abdômen agudo e tenesmo (Hedlund, 2008). Sinais de choque hemorrágico podem ocorrer se os vasos ovarianos ou uterinos forem rompidos. Outros achados incluem agitação, postura anormal, dor, inchaço perineal, lambedura e disúria. Adicionalmente, de acordo com Niles e Williams (1999), o deslocamento caudal da bexiga pode resultar em disúria e estrangúria em $20 \%$ dos casos, indicando obstrução uretral total ou parcial. Disúria e disquesia foram relatadas na paciente, porém as alterações clínicas de choque séptico estavam ausentes, apesar de intensa leucocitose. 


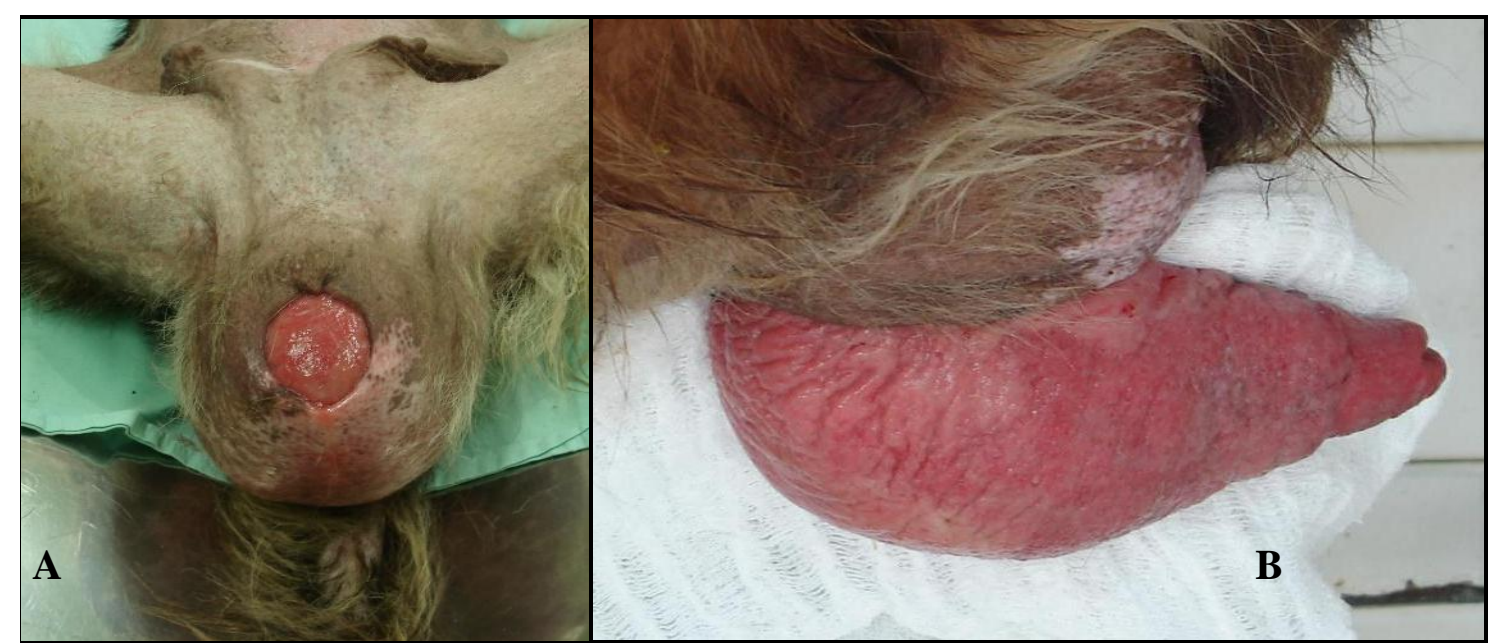

Figura 1. Cadela, Collie, 13 anos. (A) Observa-se aumento de volume em região vulvar. (B) Observa-se a massa avermelhada protruída pela abertura vulvar, diagnosticada como prolapso uterino.

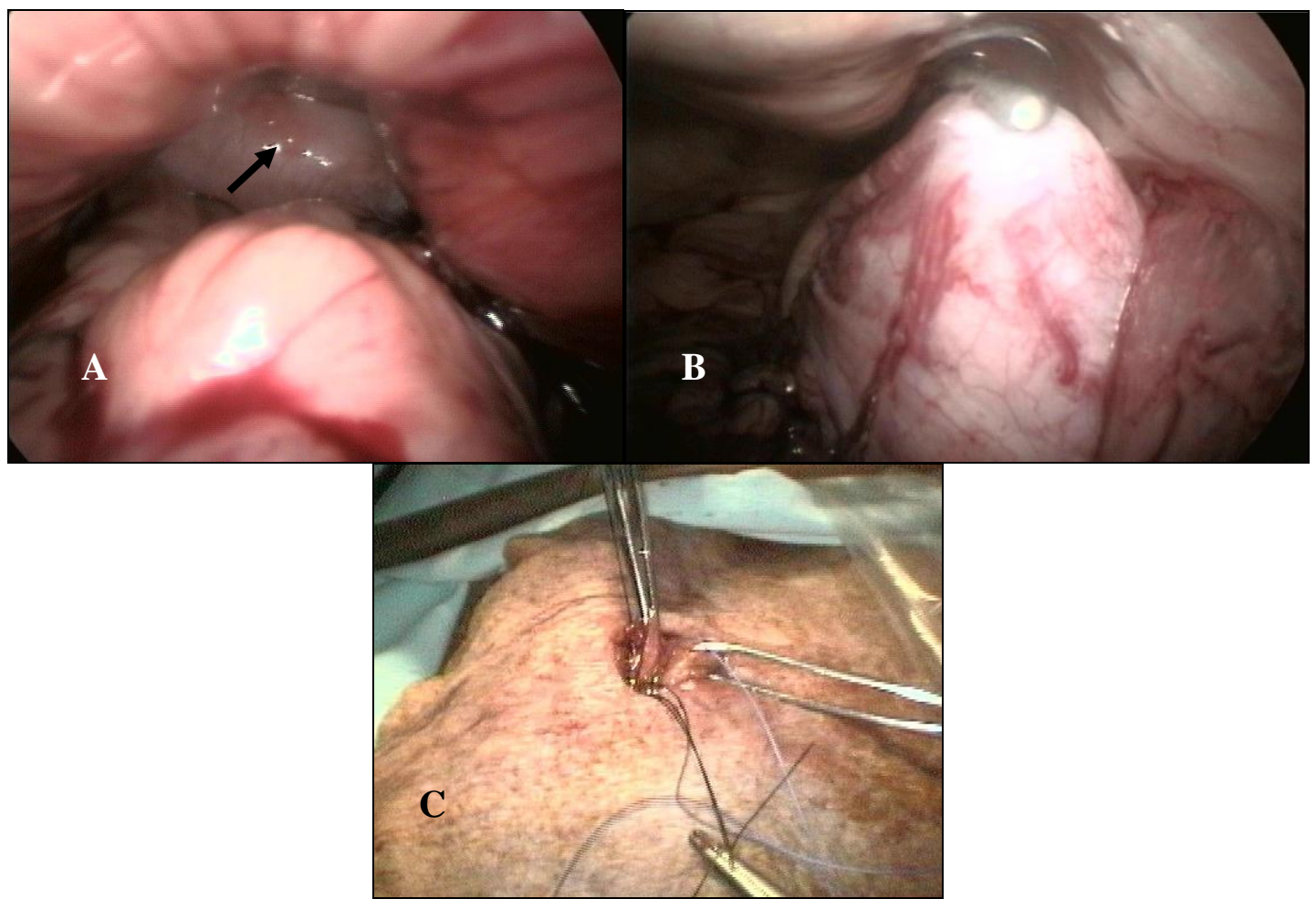

Figura 2. Cadela, Collie, 13 anos. (A) Visualização laparoscópica da vesícula urinária (seta) deslocada caudalmente em região pélvica. (B) Apreensão e tracionamento da vesícula urinária com pinça Babcock, em direção ao segundo portal laparoscópico. (C) Realização de sutura contínua simples para cistopexia através da parede abdominal externa.

O diagnóstico do prolapso uterino é direto e baseia-se na história, em sinais clínicos e no exame físico, observando-se a presença de tecido uterino protruído pela vulva (Mostachio et al., 2008). Algumas vezes, este pode não estar visível no momento do atendimento, então o exame digital pode revelar a presença de um corno uterino no canal vaginal (Stone, 2007). Juntamente com o corno uterino protruído havia um aumento de volume de consistência fluida, o qual foi posteriormente identificado como sendo a vesícula urinária. Conforme afirmam Niles e 
Willians (1999), o diagnóstico de retroflexão vesical pode ser realizado pela palpação da massa protruída de consistência macia e fluida. A radiografia e a ultrassonografia podem ser usadas para confirmar a localização vesical. Observa-se que o diagnóstico de prolapso vesical foi obtido tardiamente, durante o primeiro procedimento cirúrgico, havendo assim riscos de ocorrer lesão iatrogênica por desconhecimento da situação.

Mostachio et al. (2008) descrevem a redução manual do prolapso uterino por meio de limpeza prévia do tecido evertido com solução salina ou solução antisséptica diluída e a redução do edema com a aplicação de agentes hiperosmóticos. Como não foi possível a redução anatômica, realizou-se OSH por celiotomia. Stone (2007) relata que, caso a redução seja apenas parcial, há necessidade de laparotomia para se finalizar essa manobra por meio de tração. Após a redução, raramente há recidiva. Nessa primeira intervenção cirúrgica poderia ter sido associada uma cistopexia incisional, realizada paralelamente ao acesso da linha média ventral.

O prolapso ou protrusão da vesícula urinária para o interior da vagina é definido como cistocele (Besalti e Ergin, 2012). Em humanos, o prolapso de órgãos pélvicos (útero, bexiga, uretra e reto) é condição comum, principalmente em mulheres multíparas e submetidas a partos normais, devido à fraqueza nos tecidos responsáveis pelo suporte pélvico (Jelovsek et al.,2007). Em medicina veterinária, a cistocele é afecção raramente descrita. Esta resulta de perda de continuidade da fáscia pubocervical que funciona como suporte para a bexiga (Besalti e Ergin, 2012). Na espécie canina, a vesícula urinária é mantida em seu posicionamento pelos ligamentos presos à parede lateral da pelve e à parede abdominal ventral (Dyce et al., 2004). A anatomia da pelve e de estruturas urogenitais possui diferenças entre cães e humanos. A fáscia pubocervical está ausente nos cães (Dyce et al., 2004). Acredita-se que a vesícula urinária apresentava-se desviada caudalmente no interior do canal vaginal por não haver restrição de estruturas anatômicas como as presentes em humanos e por ter ocorrido ruptura dos ligamentos de suporte, em decorrência do esforço excessivo e do aumento da pressão intraabdominal resultantes do parto distócico.
O deslocamento da vesícula urinária deve ser tratado como caso de emergência. Deve-se prevenir que ela se desloque caudalmente; para isso, são descritos, em cães, vários procedimentos cirúrgicos, como fixação dos ductos deferentes, cistostomia e cistopexia. O método de fixação mais aceito e realizado é a cistopexia (Risselada et al., 2003). É indicada para prevenir a transformação de uma hérnia vesical recidivante em hérnia perineal e para tratamento de incontinência urinária associada à localização pélvica da bexiga (Waldron, 2007).

O tratamento proposto, neste caso, foi a cistopexia, assim como descreveram Besalti e Ergin (2012), que utilizaram a técnica para o reparo de cistocele em uma cadela, associada à colopexia para correção de prolapso de reto. Já Niles e Willians (1999) e Risselada et al. (2003) utilizaram cistopexia incisional associada à herniorrafia no manejo de retroflexão vesical e hérnia perineal em um canino e um felino, respectivamente.

Para realizar a cistopexia, é indicada a aplicação de quatro a seis pontos interrompidos simples entre o corpo vesical cranial e a parede abdominal lateral ventral, utilizando-se fio absorvível ou não absorvível. Deve-se evitar a aplicação de tensão cranial excessiva sobre a vesícula urinária, pois isto pode interferir com seu esvaziamento normal (Waldron, 2007). Besalti e Ergin (2012) utilizaram um acesso para laparotomia pela linha média ventral para visualização da vesícula urinária retroflexionada no canal pélvico e para a realização da cistopexia.

$\mathrm{Na}$ presença de recidiva, optou-se por utilizar a videocirurgia, tornando o procedimento minimamente invasivo e proporcionando melhor qualidade de visibilização da vesícula urinária em uma área pélvica restrita e de difícil acesso e visualização por meio da celiotomia convencional. Rawlings et al. (2002) relataram o desenvolvimento de duas técnicas de cistopexia por laparoscopia videoassistida em 15 cães saudáveis (oito machos e sete fêmeas) e em três cães com histórico de retroflexão vesical secundária em hérnia perineal. Utilizaram-se os princípios dessas técnicas, diferenciando-se quanto à localização paramediana dos portais, devido à presença de ferida cirúrgica prévia na linha média ventral, e quanto à aplicação de duas 
suturas contínuas simples em vez da sutura interrompida indicada pelos autores. Optou-se pela modalidade videoassistida para reduzir as dificuldades técnicas e o tempo operatório associados à técnica totalmente laparoscópica, já que o animal apresentava idade avançada e condição clínica delicada.

\section{CONCLUSÃO}

O reparo de prolapso de vesícula urinária por cistopexia videoassistida apresenta-se como possibilidade viável de tratamento para cadelas com essa alteração clínica associada ao prolapso de útero.

\section{REFERÊNCIAS}

BESALTI, O.; ERGIN, I. Cystocele and rectal prolapse in a female dog. Can. Vet. J., v.53, p.1314-1316, 2012.

DYCE, K.M.; SACK, W.O.; WENSING, C.J.G. Tratado de Anatomia Veterinária. 3.ed. Rio de Janeiro: Elsevier, 2004. p.177-180.

HEDLUND, C.S. Cirurgia do sistema reprodutivo e genital. In: FOSSUM, T.W. Cirurgia de pequenos animais. 3.ed. Rio de Janeiro: Elsevier, 2008. p.745-747.

JELOVSEK, J.E.; MAHER, C.; BARBER, M.D. Pelvic organ prolapse. Lancet., v.369, p.10271038, 2007.
MATYJASIK, H.; ADAMIAK, Z.; PESTA, W. et al. Laparoscopic procedures in dogs and cats. Pol. J. Vet. Sci., v.14, p.305-316, 2011.

MOSTACHIO, G.Q.; VICENTE, W.R.R.; CARDILLI, D.J. et al. Relato de caso - Prolapso uterino em gata e retroflexão uterina em cadela. Cienc. Anim. Bras., v.9, p.801-805, 2008.

NILES, J.D.; WILLIAMS, J.M. Perineal hernia with bladder retroflexion in a female cocker spaniel. J. Small. Anim. Pract., v.40, p.92-94, 1999.

ÖZYURTLU, N.; KAYA, D. Unilateral uterine prolapse in a cat. Turk. J. Vet. Anim. Sci., v.29, p.941-943, 2005.

RAWLINGS, C.A.; HOWERTH, E.W.; MAHAFFEY, M.B. et al. Laparoscopic-assisted cystopexy in dogs. Am. J. Vet. Res., v.63, p.1226-1231, 2002.

RISSELADA, M.; KRAMER, M.; VAN DE VELDE, B. et al. Retroflexion of the urinary bladder associated with a perineal hernia in a female cat. J. Small. Anim. Pract., v.44, p.508510, 2003.

STONE, E.A. Ovário e útero. In: SLATTER, D. Manual de cirurgia de pequenos animais. v.2, 3.ed. Barueri: Manole, 2007. p.1487-1502.

WALDRON, D.R. Bexiga. In: SLATTER, D. Manual de cirurgia de pequenos animais. v.2, 3.ed. Barueri: Manole, 2007. p.1632-1634. 